\title{
Formation of a New Cell Wall by Protoplasts of Candida albicans: Effect of Papulacandin B, Tunicamycin and Nikkomycin
}

\author{
By MARIA V. ELORZA, AMELIA MURGUI, HORTENSIA RICO, \\ FERNANDO MIRAGALL AND RAFAEL SENTANDREU* \\ Department de Microbiologia, Facultat de Farmacia, Universitat de València, \\ Avgda Blasco Ibañez 13, 46010 València, Spain
}

(Received 4 November 1986; revised 6 February 1987)

\begin{abstract}
Incorporation of polysaccharides into the walls of regenerating protoplasts of Candida albicans was followed in the presence of papulacandin B, tunicamycin and nikkomycin. With the first drug, chitin was incorporated normally whereas incorporation of glucans and mannoproteins was significantly decreased. Tunicamycin decreased incorporation of all wall polymers when added at the beginning of the regeneration process but blocked only mannan and alkaliinsoluble glucan incorporation when added after $5 \mathrm{~h}$. Nikkomycin inhibited chitin synthesis, and the walls formed by the protoplasts were enriched in alkali-soluble glucan. Pulse-chase experiments suggested that a precursor-product relationship between the alkali-soluble and alkali-insoluble glucans existed in the wall. The results obtained with the antibiotics were confirmed and extended by cytological studies using wheat-germ agglutinin labelled with colloidal gold and concanavalin A-ferritin as specific markers of chitin and mannoproteins respectively. The results support the idea that regeneration of walls by protoplasts occurs in two steps: firstly, a chitin microfibrillar skeleton is formed, and in a later step glucan-mannoprotein complexes are added to the growing structure. The chitin skeleton probably allows the orderly spatial arrangement of the other polymers giving rise to the regenerated cell wall.
\end{abstract}

\section{INTRODUCTION}

The walls of Candida albicans and other fungi are complex structures both chemically and structurally (Chattaway et al., 1968; Cassone et al., 1973; Poulain et al., 1978). Chemically they are characterized by the presence of $\beta$-glucans, chitin and mannoproteins. Glucans are the main structural component of the walls, whereas chitin is found only in small amounts (Sullivan et al., 1983). The proteins are grouped in two independent families; one of them (apparent molecular mass $150 \mathrm{kDa}$ or larger) comprises molecules with large polymannose chains (mannan) linked through $N$-glycosidic bonds, probably connected covalently to the glucan network (Shibata et al., 1983; Frevert \& Ballou, 1984; Pastor et al., 1984; Zlotnik et al., 1984; Elorza et al., 1985). The other family found in isolated walls comprises a $30 \mathrm{kDa}$ mannoprotein possessing a single $N$-linked carbohydrate chain and several low molecular mass protein species (between 15 and $80 \mathrm{kDa}$ ) most of which lack $N$-glycosidic linkages: they are associated with the wall structure by non-covalent bonds and their physiological significance is unknown (Pastor et al., 1984; Elorza et al., 1985).

The architecture of the cell walls is not well defined (Farkaš, 1985), but it has been described as being a multilayered structure (Cassone et al., 1979; Hilenski et al., 1986) with a fine network of microfibrils, probably chitin, in its inner part (Tronchin et al., 1981; Kopecká, 1984).

Localization of the mannoproteins in the walls has been investigated by the use of specific

Abbreviations: Au-WGA, wheat-germ agglutinin complexed with colloidal gold; Con A-fe, concanavalin A-ferritin; I-glucan, alkali-insoluble glucan; S-glucan, alkali-soluble glucan. 
antibodies, lectin binding, extraction with solvents, scanning and transmission electron microscopy, and enzyme digestion. The results obtained suggest that they are concentrated on the external surface of the wall and next to the plasma membrane (Shepherd et al., 1985). In normal growing cells, incorporation of covalently linked mannoproteins into the wall structure seems to require concomitant formation of glucan (Murgui et al., 1985).

Various antibiotics have been reported to interfere with the normal formation of fungal walls: nikkomycins are inhibitors of chitin synthesis (Gooday et al., 1985; Hector \& Braun, 1986); papulacandin B interferes with formation of glucans (Baguley et al., 1979; Kopecká, 1984; Pérez et al., 1983); and tunicamycin is an inhibitor of the $N$-glycosylation of mannoproteins (Lehle \& Tanner, 1976; Tkacz \& Lampen, 1975).

Formation of the wall structure has been studied in Saccharomyces cerevisiae (Necas \& Svoboda, 1985) and other fungal protoplasts, but rather little information has been obtained as their regeneration capacity in liquid media is limited. However, protoplasts of $C$. albicans revert to normally growing cells (Miragall et al., 1986; Murgui et al., 1986). In the present work, we extend our previous observations on the regeneration of the cell wall by $C$. albicans protoplasts and on the effect of the inhibition of synthesis of some wall polymers on the incorporation of specific mannoproteins into the wall (Murgui et al., 1986). We also report the electron microscopic localization of chitin with wheat-germ agglutinin complexed with colloidal gold and of mannoproteins with concanavalin A-ferritin.

\section{METHODS}

Organism, growth and preparation of protoplasts. C. albicans ATCC 26555 was used; it was maintained by subculturing every 2-3 weeks on slopes of Sabouraud dextrose agar and propagated in Lee medium (Lee et al., 1975). Protoplasts were prepared as described by Elorza et al. (1983).

Regeneration of protoplasts and radioactive labelling. Protoplasts adjusted to $\mathrm{OD}_{600} 0.22$ as measured with a Perkin Elmer Coleman 250 spectrophotometer were suspended in Lee medium $(20 \mathrm{ml})$ supplemented with 0.6 $\mathrm{M}-\mathrm{KCl}$ in individual flasks and incubated at $28^{\circ} \mathrm{C}$. Each incubation contained $0.4 \mu \mathrm{Ci}\left[\mathrm{U}-{ }^{14} \mathrm{C}\right.$ ]glucose $(0.24 \mathrm{Ci}$ $\left.\mathrm{mmol}^{-1} ; 8.88 \mathrm{GBq} \mathrm{mmol}{ }^{-1}\right) \mathrm{ml}^{-1}$ and continued for the indicated times. In some cases, papulacandin B $\left(5 \mu \mathrm{g} \mathrm{ml}^{-1}\right)$, nikkomycin $\left(50 \mu \mathrm{g} \mathrm{ml}^{-1}\right)$, tunicamycin $\left(20 \mu \mathrm{g} \mathrm{ml}^{-1}\right)$ or trichodermin $\left(2 \mu \mathrm{g} \mathrm{ml}^{-1}\right)$ were added to the regeneration medium. The stock solutions were: papulacandin, $5 \mathrm{mg} \mathrm{ml}^{-1}$ in methanol; nikkomycin, $1 \mathrm{mg} \mathrm{ml}^{-1}$ in water; tunicamycin, $2 \mathrm{mg} \mathrm{ml}^{-1}$ in $50 \mathrm{~mm}-\mathrm{NaOH}$ and trichodermin, $2 \mathrm{mg} \mathrm{ml}^{-1}$ in dimethyl sulphoxide.

Preparation of walls and isolation of polysaccharide fractions. Protoplast cultures were taken at intervals and collected by centrifugation $(1200 \mathrm{~g}$ for $10 \mathrm{~min}$ ). The protoplasts were washed with $0.6 \mathrm{M}-\mathrm{KCl}$, broken by shaking with glass beads in a vortex mixer (three periods of $20 \mathrm{~s}$ ), and the walls were sedimented $(1200 \mathrm{~g}$ for $10 \mathrm{~min}$ ) and purified as described by Elorza et al. (1985). Walls were extracted with $2 \mathrm{M}-\mathrm{NaOH}$ at $100^{\circ} \mathrm{C}$ for $90 \mathrm{~min}$; the insoluble residue was removed by centrifugation $(1200 \mathrm{~g}$ for $10 \mathrm{~min})$ and washed with distilled water. One part of the alkali-soluble supernatant was treated with Fehling's solution (Haworth et al., 1941) and the precipitate collected (mannan fraction); the other part was precipitated by adding 3 vols ethanol [mannan plus alkali-soluble glucan (S-glucan)]. The actual value of S-glucan was obtained by subtracting the latter value from that obtained for mannan. The alkali-insoluble residue was extracted with $0.5 \mathrm{M}$-acetic acid at $100^{\circ} \mathrm{C}(90 \mathrm{~min})$. The supernatant was discarded and the residue washed extensively with distilled water. Part of this fraction containing alkali-insoluble glucan (I-glucan) plus chitin was collected on glass fibre filters (Schleicher \& Schuell). After drying, the filters were counted in a Beckman scintillation spectrometer (model 7500) using toluene-based scintillation fluid. The remaining fraction was mixed with Zymolyase $20 \mathrm{~T}$ (a glucanase complex) $\left(2 \mathrm{mg} \mathrm{ml}^{-1}\right)$ in $2 \mathrm{ml} 0.1 \mathrm{M}$-sodium acetate buffer pH 5.6 and incubated for $4 \mathrm{~h}$ at $30^{\circ} \mathrm{C}$ to remove the glucan present. The radioactivity in the insoluble residue was determined (chitin).

Analysis of the spent medium. The medium obtained after incubation of protoplasts $(20 \mathrm{ml})$ was dialysed against distilled water at $4{ }^{\circ} \mathrm{C}$ (three times, $24 \mathrm{~h}$ each) and concentrated to $5 \mathrm{ml}$ with polyethylene glycol (molecular mass 3350). The medium was then divided in two portions; one was treated with Fehling's solution (mannoproteins) and the other was precipitated by adding 3 vols ethanol (total polysaccharides).

Preparation of samples for transmission electron microscopy. Isolated walls were fixed in $0.1 \mathrm{M}$-phosphate buffer $\mathrm{pH} 7.0$ containing $2.5 \%(\mathrm{v} / \mathrm{v})$ glutaraldehyde $(1 \mathrm{~h})$. After three washings with the phosphate buffer, walls were suspended in $0.05 \mathrm{M}-\mathrm{Tris} / \mathrm{HCl} \mathrm{pH} 7.0,0.15 \mathrm{M}-\mathrm{NaCl}, 1 \mathrm{mM}-\mathrm{CaCl}_{2}, 1 \mathrm{~mm}-\mathrm{MnCl}_{2}, 1 \mathrm{mM}-\mathrm{MgCl}_{2}$ containing concanavalin A-ferritin (Con A-fe) $\left(0.5 \mathrm{mg} \mathrm{m}^{-1}\right)$ and incubated for $30 \mathrm{~min}$ at room temperature. The samples were processed for conventional electron microscopy according to Spurr (1969). Thin sections of the partially regenerated walls of protoplasts incubated under different conditions and labelled with Con A-fe were floated for I h on wheat-germ agglutinin complexed with colloidal gold (Au-WGA) prepared according to Geoghegan \& 
Ackerman (1977), and deposited on copper grids. All specimens were examined in a Jeol 100s electron microscope operating at $60 \mathrm{kV}$.

Chemicals. Zymolyase 20T was purchased from Miles Laboratories. Papulacandin B was a gift from Ciba Geigy, Basel, Switzerland. Trichodermin was kindly provided by Dr A. Jiménez, Centro de Biología Molecular, Madrid, Spain. Nikkomycin, a complex of nikkomycin Z and nikkomycin X as major components, was a generous gift of Bayer AG. $\left[\mathrm{U}^{-1+} \mathrm{C}\right]$ Glucose was purchased from Amersham, and tunicamycin, Con A-fe and wheat-germ agglutinin from Sigma.

\section{RESULTS}

Synthesis of cell wall polymers by protoplasts

The kinetics of incorporation of mannoproteins into the cell walls of regenerating protoplasts after incubation in the presence of $\left[\mathrm{U}-{ }^{1+} \mathrm{C}\right]$ protein hydrolysate had been determined previously (Murgui et al., 1986), but it was of interest to learn how they and other polymers interacted once synthesized and before being incorporated into the walls. With this aim, protoplasts were incubated in an osmotically protected medium with $\left[\mathrm{U}^{-1+} \mathrm{C}\right] \mathrm{glucose}$ as a precursor of polysaccharides and supplemented with papulacandin B, nikkomycin or tunicamycin.

When the protoplasts were regenerated in the presence of papulacandin $\mathrm{B}$, the distribution of label into various wall polysaccharides changed with respect to control cultures. Chitin, the first polymer detected on the protoplast surface (Murgui et al., 1986), was incorporated normally whereas incorporation of the S- and I-glucans was significantly decreased (Table 1). Accumulation of mannoproteins on the walls was also affected, being reduced to $11 \%$ after $5 \mathrm{~h}$ of incubation. [We have recently found a similar result with respect to mannoprotein incorporation in $S$. cerevisiae using aculeacin $\mathrm{A}$, another antibiotic that inhibits glucan formation (Valentin et al., 1986).] These results indicated that the synthesis of chitin and its incorporation into the wall were independent of the presence of the other polysaccharides, and that glucan inhibition also interfered with incorporation of mannoprotein into the growing wall.

In the presence of tunicamycin, incorporation of mannoproteins into the regenerating walls was brought to a halt, suggesting that some proteins of the wall need polymannose chains for correct incorporation into the growing wall structure. Tunicamycin also decreased the formation of glucans and chitin (Table I). This result is interesting because at the concentration used, the drug caused only $20 \%$ inhibition of total cell protein synthesis after $5 \mathrm{~h}$ of incubation (data not shown), suggesting that the glucan- and chitin-synthases might be mannoproteins or that their transport is indirectly blocked by the drug (see below).

Nikkomycin blocked formation of chitin by $85 \%$; in its presence the amount of I-glucan found on the walls was lower than in the control whereas that of S-glucan was higher (Table 1). These results suggest that chitin must be present on the surface of the protoplasts before incorporation of the I-glucan can take place. In parallel with the low levels of chitin and I-glucan, mannoprotein incorporation in the presence of the drug was also significantly reduced.

Since mannoprotein incorporation into the walls was greatly decreased in the presence of the antibiotics, the possibility that mannoproteins accumulated in the growth medium was examined. Accumulation of mannoproteins in spent medium was detected in the presence of nikkomycin and papulacandin B, but not in the presence of tunicamycin (Table 2). Other ethanol-precipitable materials were also found in higher amounts in the presence of nikkomycin (Table 2) but they were not further analysed. These results indicate that nikkomycin and papulacandin B did not prevent the synthesis of mannoproteins, but blocked their incorporation into the growing wall, probably as a side effect of the inhibition of formation of the chitin and $\beta$-glucan skeletons, respectively, on the protoplast surface.

\section{Effect of antibiotics added at different ttmes during the regeneration process}

As tunicamycin added at the beginning of the regeneration process decreased the formation of all cell-wall polymers (Table 1), and in order to obtain more information about the initial steps of wall formation, the antibiotics were added at different times during regeneration. First, the 
Table 1. Effect of papulacandin B, tunicamycin and nikkomycin on the distribution of label from $\left[U-{ }^{14} \mathrm{C}\right] \mathrm{glucose}$ into various polysaccharide fractions of regenerating protoplasts

Different suspensions $(20 \mathrm{ml})$ of protoplasts $\left(\mathrm{OD}_{600} 0.22\right)$ were regenerated in stabilized Lee medium containing [ $\left.\mathrm{U}^{-14} \mathrm{C}\right] \mathrm{glucose}\left(0.4 \mu \mathrm{Ci} \mathrm{m}{ }^{-1}\right)$ in the absence or presence of antibiotics added at the start of the regeneration. After 3,5 and $7 \mathrm{~h}$ incubation at $28^{\circ} \mathrm{C}$, protoplasts were collected and the walls isolated and fractionated as described in Methods. The radioactivity in each fraction is expressed as total c.p.m. (mean of three experiments); values in parentheses represent percentage incorporation relative to the control.

$\begin{array}{ccccrr}\begin{array}{c}\text { Incubation } \\ \text { conditions }\end{array} & \begin{array}{c}\text { Regeneration } \\ \text { time }(\mathrm{h})\end{array} & \text { Mannan } & \text { S-glucan } & \text { I-glucan } & \text { Chitin } \\ \text { Control } & 3 & 2100 & 6960 & 7800 & 25600 \\ & 5 & 22650 & 13910 & 31500 & 58600 \\ & 7 & 47640 & 24360 & 75050 & 95410 \\ \text { Papulacandin B } & 3 & 670(31 \cdot 9) & 910(13 \cdot 1) & 3830(49 \cdot 1) & 21570(84 \cdot 3) \\ \left(5 \mu \mathrm{g} \mathrm{ml}^{-1}\right) & 5 & 2600(11 \cdot 5) & 1930(13 \cdot 9) & 9190(29 \cdot 2) & 52000(88 \cdot 7) \\ & 7 & 5330(11 \cdot 2) & 3570(14 \cdot 7) & 16540(22 \cdot 0) & 110190(116 \cdot 2) \\ \text { Tunicamycin } & 3 & 580(27 \cdot 6) & 2600(37 \cdot 4) & 2470(31 \cdot 7) & 7960(31 \cdot 0) \\ \left(20 \mu \mathrm{g} \mathrm{ml}^{-1}\right) & 5 & 950(4 \cdot 2) & 5190(37 \cdot 3) & 7540(23 \cdot 9) & 12080(20 \cdot 6) \\ & 7 & 1010(2 \cdot 1) & 4060(16 \cdot 7) & 11770(15 \cdot 7) & 14630(15 \cdot 3) \\ \text { Nikkomycin } & 3 & 900(42 \cdot 9) & 5300(76 \cdot 1) & 3900(50 \cdot 0) & 2050 \\ \left(50 \mu \mathrm{g} \mathrm{ml}^{-1}\right) & 5 & 2140(9 \cdot 4) & 17000(122 \cdot 2) & 6930(22 \cdot 0) & 8760)(14 \cdot 9) \\ & 7 & 4770(10 \cdot 0) & 30730(126 \cdot 1) & 16510(22 \cdot 0) & 14360(15 \cdot 0)\end{array}$

Table 2. Polysaccharides accumulated in the regeneration medium of C. albicans protoplasts incubated in the presence of antibiotics

\begin{tabular}{|c|c|c|c|}
\hline Incubation conditions & $\begin{array}{l}\text { Regeneration } \\
\text { time (h) }\end{array}$ & Mannan & Glucan \\
\hline Control & $\begin{array}{l}3 \\
5 \\
7\end{array}$ & $\begin{array}{l}10680 \\
37150 \\
38650\end{array}$ & $\begin{array}{r}5840 \\
14140 \\
24360\end{array}$ \\
\hline Papulacandin B $\left(5 \mu \mathrm{g} \mathrm{ml}^{-1}\right)$ & $\begin{array}{l}3 \\
5 \\
7\end{array}$ & $\begin{array}{l}13600(127) \\
45340(122) \\
79160(205)\end{array}$ & $\begin{array}{r}5520(95) \\
14220(101) \\
17920(74)\end{array}$ \\
\hline Tunicamycin $\left(20 \mu \mathrm{g} \mathrm{ml}^{-1}\right)$ & $\begin{array}{l}3 \\
5 \\
7\end{array}$ & $\begin{array}{cc}2040 & (19) \\
3340 & (9.0) \\
3690 & (9.5)\end{array}$ & $\begin{array}{r}7930(136) \\
19260(136) \\
36620(150)\end{array}$ \\
\hline Nikkomycin $\left(50 \mu \mathrm{g} \mathrm{ml}^{-1}\right)$ & $\begin{array}{l}3 \\
5 \\
7\end{array}$ & $\begin{array}{r}13740(129) \\
65730(177) \\
125810(325)\end{array}$ & $\begin{array}{l}11120(190) \\
19520(138) \\
31240(128)\end{array}$ \\
\hline
\end{tabular}

effect of inhibition of protein synthesis on wall formation was studied. Trichodermin, which at $2 \mu \mathrm{g} \mathrm{ml}^{-1}$ suppressed protein synthesis by $93 \%$ (results not shown), blocked incorporation of all cell-wall polymers when added at the beginning of the incubation period. When the drug was added $3 \mathrm{~h}$ after the onset of regeneration, thus allowing initial protein synthesis and deposition of the chitin skeleton, mannoprotein incorporation stopped, chitin deposition was not affected, incorporation of I-glucan decreased to $70 \%$ of the control and that of S-glucan was totally inhibited (Fig. 1). After $7 \mathrm{~h}$ incubation, incorporation of chitin was still $80 \%$ relative to the control. These results indicated that the cell machineries for synthesizing chitin and glucans are stable systems which remain active for long periods; once synthesized, they are not affected by the drug, whereas the formation of mannoproteins requires the continuous synthesis and glycosylation of protein, as in S. cerevisiae (Elorza \& Sentandreu, 1969). 


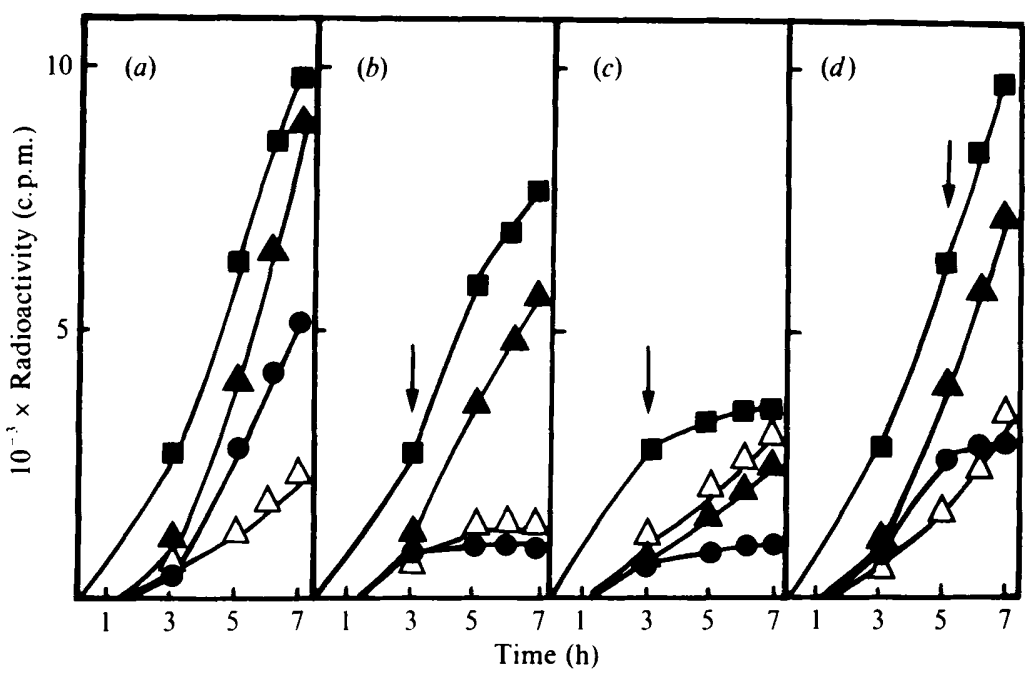

Fig. 1. Distribution of radioactivity among the polysaccharide fractions during regeneration of protoplasts. Various suspensions $(20 \mathrm{ml})$ of protoplasts $\left(\mathrm{OD}_{600} 0 \cdot 22\right)$ were regenerated in osmotically stabilized Lee medium in the presence of $0 \cdot 4 \mu \mathrm{Ci}\left[\mathrm{U}^{-1+} \mathrm{C}\right]$ glucose $\mathrm{ml}^{-1}$. (a) Control culture without antibiotics; $(b)$ trichodermin or $(c)$ nikkomycin added after $3 \mathrm{~h}$ of regeneration; $(d)$ tunicamycin added after $5 \mathrm{~h}$ of regeneration. At the times indicated samples were taken, walls were isolated and the radioactivity in the polysaccharide fractions was determined: $\square$, chitin; $\Delta, I$-glucan; $\triangle, S$-glucan; $\boldsymbol{O}$, mannan.

Addition of nikkomycin after $3 \mathrm{~h}$ regeneration resulted in an almost complete blockage of new chitin incorporation as well as that of I-glucan and mannoproteins. Incorporation of S-glucan, on the other hand, was not inhibited but even stimulated (Fig. 1). These results agreed with those found when the antibiotic was added at the beginning of the regeneration process (Table 1).

Tunicamycin when added initially or $3 \mathrm{~h}$ after the onset of regeneration process gave similar results (Table 1). However, when tunicamycin was added after $5 \mathrm{~h}$, mannoprotein synthesis was severely inhibited, and chitin was found in amounts similar to those in the control walls. After $2 \mathrm{~h}$ in the presence of this antibiotic, the amount of I-glucan was slightly decreased $(20 \%)$ with a slight increase in the S-glucan.

\section{Relationship between the S-glucan and the I-glucan}

Some of the above results suggested a possible precursor-product relationship between $\mathrm{S}$ - and I-glucans in C. albicans similar to that described in Schizophyllum commune (Sonnenberg et al., 1982). In order to obtain further information on this, the radioactivity incorporated into the wall glucans of regenerating protoplasts after a pulse of $\left[U-{ }^{14} \mathrm{C}\right]$ glucose was followed. The label found in the S-glucan after $45 \mathrm{~min}$ chase was only $13 \%$ of the radioactivity originally incorporated, with a parallel increase in c.p.m. in I-glucan (Table 3). Further information about the conversion of the S-glucan to I-glucan was obtained when the radioactive pulse was carried out in the presence of nikkomycin to block chitin formation. Again, the only polymer whose label was practically blocked during the chase period was that of the S-glucan (Table 3). The results obtained are consistent with the notion of a precursor-product relationship between the $\mathrm{S}$ - and Iglucan.

\section{Ultrastructural studies}

In order to learn how the different polymers are deposited during regeneration, ultrastructural studies were also done. Protoplasts were cultivated for $3 \mathrm{~h}$ and $5 \mathrm{~h}$ in the presence of antibiotics, and the isolated walls were labelled with Con A-fe and Au-WGA. After $3 \mathrm{~h}$ of regeneration, gold particles were uniformly distributed upon a material of low electron density and resembling wall 
Table 3. Distribution of radioactivity in a pulse-chase experiment among various wall polymers during the regeneration of $C$. albicans protoplasts in the absence (expt $A)$ and presence (expt $B)$ of nikkomycin

\begin{abstract}
Different suspensions $(20 \mathrm{ml})$ of protoplasts were incubated in osmotically protected Lee medium. After $4.5 \mathrm{~h}$ (expt A) or $3 \mathrm{~h}$ (expt B) of regeneration, the protoplasts were supplemented with [ $\mathrm{U}^{-14} \mathrm{C}$ ]glucose $\left(0.8 \mu \mathrm{Ci} \mathrm{ml}{ }^{-1}\right.$ in $\mathrm{A} ; 0.4 \mu \mathrm{Ci} \mathrm{ml}^{-1}$ plus $20 \mu \mathrm{g} \mathrm{nikkomycin} \mathrm{ml}^{-1}$ in B), and after $30 \mathrm{~min}$ (A) or $2 \mathrm{~h}(\mathrm{~B})$ they were transferred to prewarmed non-radioactive medium. At the times indicated samples were taken and the wall polymers extracted. Radioactivity is expressed as total c.p.m. (mean of three experiments); values in parentheses represent percentage incorporation relative to the chase at time 0 .
\end{abstract}

$\begin{array}{cllll}\begin{array}{c}\text { Chase period } \\ \text { (min) }\end{array} & \text { Mannan } & \text { S-glucan } & \text { I-glucan } & \text { Chitin } \\ \begin{array}{clll}\text { Expt A } \\ 0\end{array} & 10005 & 5000 & 9840 & 7774 \\ 45 & 11900(119) & 636(13) & 13190(134) & 10970(141) \\ 90 & 12700(127) & 1412(28) & 13398(136) & 11318(146) \\ \text { Expt B } & & & & \\ 0 & 4000 & 7934 & 1424 & 5450 \\ 45 & 8660(217) & 5662(71 \cdot 4) & 3358(235 \cdot 8) & 8662(158.9) \\ 90 & 8968(224) & 4954(62 \cdot 4) & 4358(306.0) & 9566(175 \cdot 5)\end{array}$

ghosts. The latter seemed to be the very first material deposited on the surface of regenerating protoplasts, confirming previous analytical and cytological observations that indicated it to be chitin (Elorza et al., 1983; Murgui et al., 1986). This initial fibrillar skeleton retained mannoproteins from the very beginning (Elorza et al., 1985; Sentandreu et al., 1983), as some Con A-fe receptors were also clearly seen associated within the fibrillar structures (Fig. 2).

When protoplasts were regenerated for $5 \mathrm{~h}$, the appearance of the wall was clearly different. The walls showed a thick electron-transparent layer with many Con A receptors on both surfaces. The Au-WGA receptors seemed to be located preferentially in the inner part of the wall extending to the nearby transparent layer as observed in whole cells (Hilenski et al., 1986). The two surfaces seemed to be enriched in glycoproteins, as Con A-fe markers were present in high amounts (Fig. $2 b$ ). When the walls were boiled in SDS only some of the Con A-fe receptors disappeared and it then seemed that the receptors located on the outer surface were more abundant than in the inner part of the wall (Fig. 2c). When the walls were treated with Zymolyase their appearance changed dramatically. The electron-transparent layer completely disappeared, as well as almost all the Con A receptors. Only a material of low electron density which could be marked with colloidal gold and had a few Con A-fe receptors was detected (Fig. $2 d$ ). These wall remains resembled the walls formed by $3 \mathrm{~h}$ regenerating protoplasts (Fig. $2 a$ ).

Walls obtained from protoplasts which had been incubated in the presence of tunicamycin or papulacandin B were also characteristic. The walls obtained from tunicamycin-treated protoplasts were thinner than those of control protoplasts, and almost completely lacked the electron-transparent layer, which was substituted by a material of low electron density that was randomly labelled with $\mathrm{Au}-\mathrm{WGA}$ and had very few Con A-fe receptors distributed throughout the structure (Fig. $3 a$ ). These receptors probably corresponded to the very few mannoprotein molecules incorporated, as the drug suppressed glycosylation of proteins (Table 1) and the walls were similar to those found in $3 \mathrm{~h}$ regenerating protoplasts or after $5 \mathrm{~h}$ following Zymolyase treatment (Fig. 2). Treatment of these walls with SDS did not modify the basic appearance of the walls although the Con A-fe receptors almost disappeared (Fig. $3 b$ ).

When the protoplasts were incubated for $5 \mathrm{~h}$ in the presence of papulacandin $\mathrm{B}$ under conditions in which $70 \%$ of glucan synthesis was inhibited, the isolated walls showed a material of low electron density interspersed with large amounts of gold markers (Fig. 3c). Con A receptors did not disappear when these walls were treated with SDS (data not shown), suggesting that the small amounts of $\beta$-glucans incorporated in the presence of the drug (about $30 \%$ of the control walls) were also able to retain some mannoproteins. 

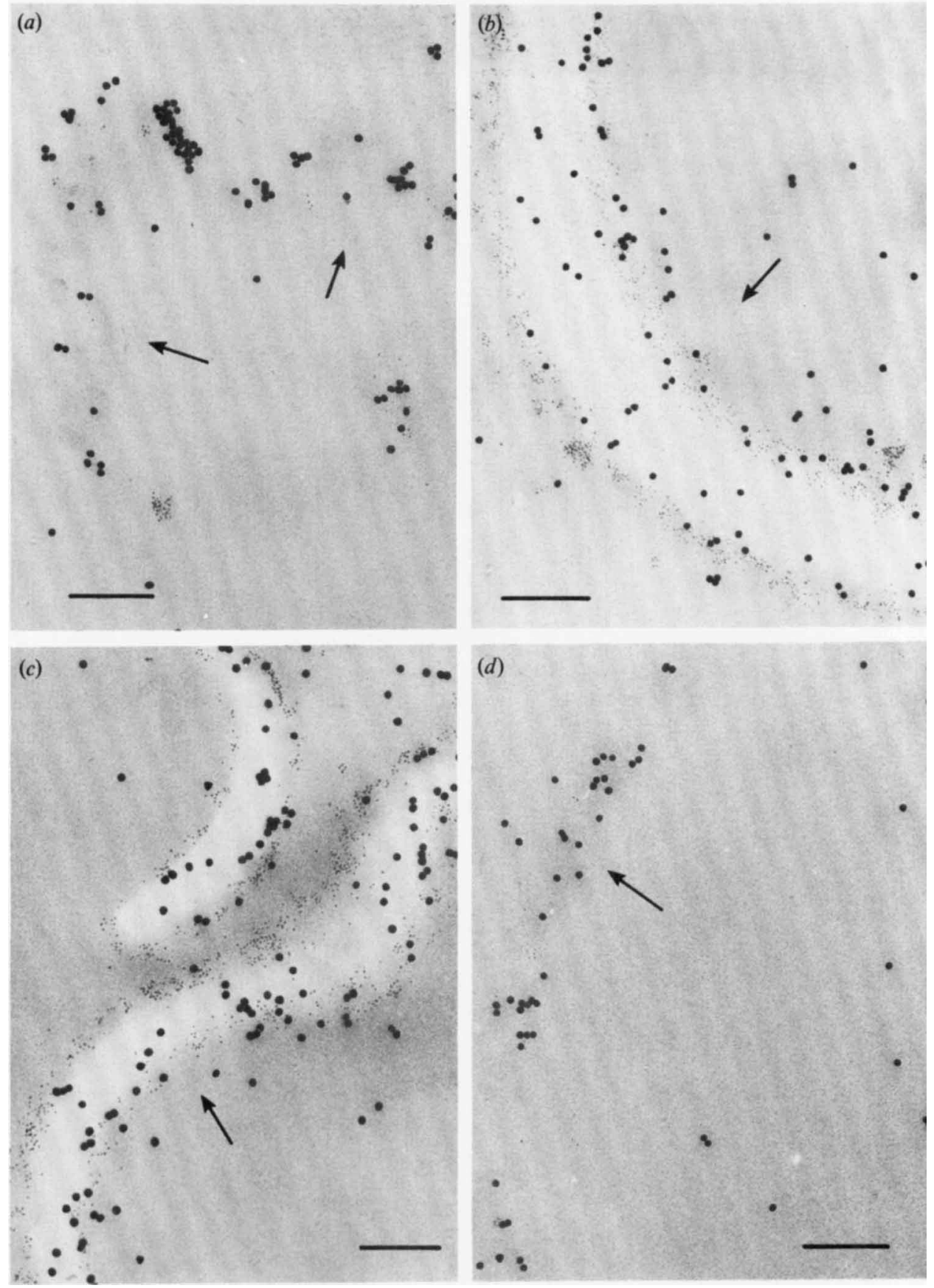

Fig. 2. Isolated walls obtained from protoplasts of $C$. albicans regenerated for $3 \mathrm{~h}(a)$ and $5 \mathrm{~h}(b)$. Walls of the latter protoplasts were also extracted with SDS $(c)$ or Zymolyase $(d)$. Chitin was detected with AuWGA (large label) and mannoproteins with Con A-fe (small label). Arrows indicate the inner surface of the walls. Bars, $0 \cdot 2 \mu \mathrm{m}$. 

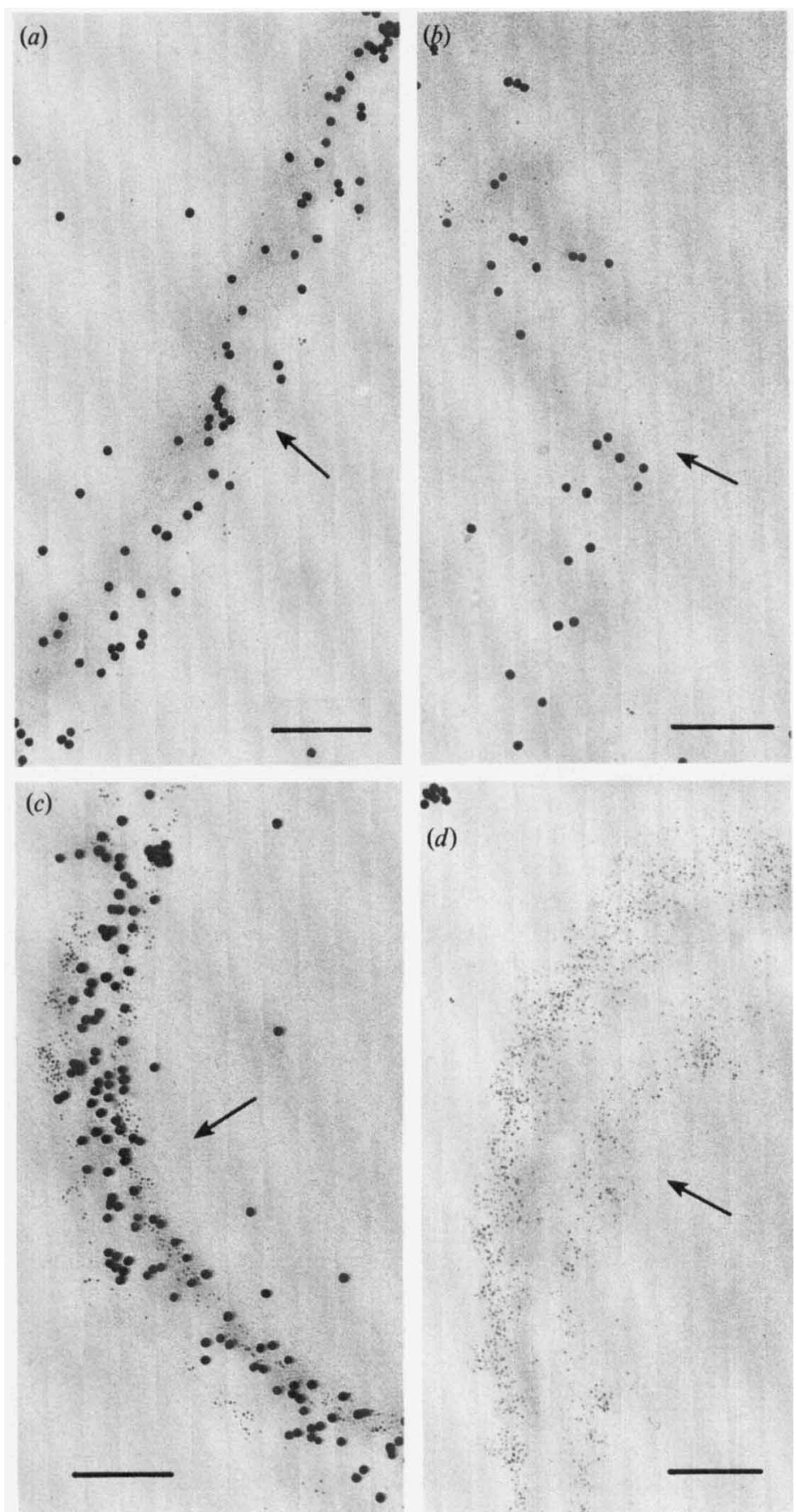

sts

(d)

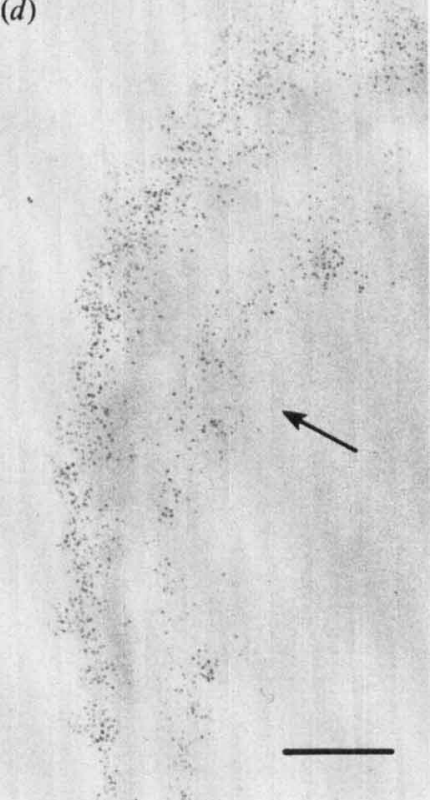

Fig. 3. Isolated walls obtained from protoplasts of $C$. albicans incubated in regeneration medium for $5 \mathrm{~h}$ in the presence of tunicamycin prior to $(a)$ or after $(b)$ extraction with SDS, or in the presence of papulacandin B $(c)$ or nikkomycin $(d)$. Chitin and mannoproteins were detected as in Fig. 2. Arrows indicate the inner surface of the walls. Bars, $0 \cdot 2 \mu \mathrm{m}$. 
In the presence of nikkomycin the protoplasts formed walls which were not labelled by AuWGA, although the Con A-fe receptors were present as well as some electron-transparent material (Fig. 3d), confirming that in the presence of this antibiotic chitin was not synthesized but the S-glucan (Table 1) was able to form an abnormal wall (Hilenski et al., 1986).

\section{DISCUSSION}

Formation of a new wall by fungal protoplasts is initiated by deposition of a chitin skeleton which allows incorporation of other wall polymers (Elorza et al., 1983; Gibson et al., 1976; Murgui et al., 1986). This is interesting, as chitin is a minor component of the wall of normal growing cells, suggesting that the walls formed by protoplasts are initially abnormal structures, as previously reported (Nečas \& Svoboda, 1985).

In the case of $C$. albicans in the presence of nikkomycin, a potent competitive inhibitor of chitin synthase (Gooday et al., 1985; Gow \& Selitrennikoff, 1984; Hector \& Braun, 1986), synthesis of this skeleton was severely reduced (Table 1, Fig. 3) with the formation of an abnormal wall characterized by greater amounts of S-glucan and very low concentrations of I-glucan and mannoproteins. As the S-glucan seems to be the precursor of the I-glucan, it appears that this conversion needs the previous presence of chitin in the newly formed walls. This interpretation would be in agreement with the reported existence of covalent bridges between chitin and glucan in other fungal cells (Stagg \& Feather, 1973). Polyoxin D, another inhibitor of chitin synthase, blocks formation of chitin and I-glucan in Schizophyllum commune, but not accumulation of the S-glucan (de Vries \& Wessels, 1975). We speculate that in $C$. albicans, as in Schiz. commune (Sietsma \& Wessels, 1981 ; Sonnenberg et al., 1982), a progressive cross-linking between S-glucan and chitin occurs during normal extension of the wall, changing the solubility characteristic of the former polymer. In the absence of chitin, the process does not occur and, consequently, the solubility characteristic of the S-glucan does not change. This view is supported by the fact that when nikkomycin was added $3 \mathrm{~h}$ after the initiation of regeneration (that is, when the initial chitin skeleton had already been formed) accumulation of I-glucan was again reduced whereas S-glucan was incorporated in higher amounts. When nikkomycin was present from the beginning of the regeneration process, the wall formed by the protoplasts lacked not only chitin and I-glucan but also mannoproteins, suggesting that they are also probably incorporated in a coordinated way with glucan into the growing cell wall (see below). However, they do not seem to be essential components in the process of connecting glucan subunits to the chitin network, since tunicamycin did not suppress it when added $3 \mathrm{~h}$ after the onset of the regeneration process.

Baguley et al. (1979) reported that papulacandin B inhibited glucan synthesis, and we have found that under these conditions formation of the chitin network takes place normally. However, incorporation of mannoproteins, but not their synthesis, is prevented, as they could be recovered from the regeneration medium (Table 2) (Murgui et al., 1986). These results confirm that formation of the initial chitin skeleton is completely independent of the other wall polymers, and that incorporation of mannoproteins into the growing structure takes place only in a coordinated way with the formation of I-glucan.

The analytical results were confirmed and extended by the cytochemical localization of polymers in the walls formed by protoplasts in the presence of antibiotics. Chitin was marked with WGA, a lectin that binds to $(1 \rightarrow 4)-\beta$ - $N$-acetylglucosamine residues, complexed to colloidal gold (Horisberger \& Vonlanthen, 1977; Molano et al., 1980; Roberts et al., 1983). Incorporation of mannoproteins was followed with ferritin-labelled concanavalin $\mathrm{A}$, a lectin that binds to $\alpha$-linked mannose and glucose residues. This lectin does not react with the other polysaccharides present in $C$. albicans cell walls (Tronchin et al., 1979). Initially, protoplasts formed a net of chitin (Fig. 2). A thick layer of $\beta$-glucan, marked neither by Au-WGA nor by Con A-fe, was then deposited; this layer disappeared with Zymolyase digestion and did not appear in the presence of papulacandin B. The glucan layer was covered with mannose-containing compounds which were probably mannoproteins, possibly covalently bonded to the wall structure as they were not removed by SDS, and could only be eliminated by Zymolyase digestion (Fig. 2). 
Fractionation of the wall material formed in the presence of nikkomycin demonstrated that $\mathrm{S}$ glucan was probably the main polymer present (Table 1). Mannoproteins were not incorporated (Table 1), but accumulated in the medium (Table 2). In these circumstances the morphogenetic capacity of the protoplasts was reduced and they did not revert to normal growing cells.

The results reported in this and other papers suggest that building of the walls by protoplasts occurs in two steps: ( $a$ ) formation of the chitin microfibrillar skeleton, and $(b)$ incorporation of glucans and mannoproteins which give rise to a defined mould responsible for the specific wall and cell morphologies (Elorza et al., 1985). This hypothesis is also supported by the fact that an initial deposition of chitin occurs not only during protoplast regeneration but also during normal apical growth (Cabib, 1981; Wessels et al., 1983) and in the formation of the cross-septum during cell division (Cabib, 1981), suggesting that this polymer is principally responsible for the wall ontogeny. Glucans and mannoproteins are then deposited, being the main morphogenetic components of the walls.

This work was supported by Grants from the Comisión Asesora de Investigación Científica y Técnica (3432-83) and the Fondo de Investigaciones Sanitarias. A.M. is the recipient of a predoctoral grant from the Fondo de Investigaciones Sanitarias. M.V.E. is on leave from the Instituto de Microbiología Bioquímica, CSIC Salamanca.

\section{REFERENCES}

Baguley, B. C., Rommele, G., Gruner, J. \& Wehrli, W. (1979). Papulacandin B: an inhibitor of glucan synthesis in yeast spheroplasts. European Journal of Biochemistry 97, 345-351.

CABIB, E. (1981). Chitin: structure, metabolism and regulation of biosynthesis. In Plant Carbohydrates II (Encyclopedia of Plant Physiology New Series vol. 13B), pp. 395-411. Edited by W. Tanner \& F. A. Loewus. Berlin, Heidelberg \& New York: SpringerVerlag.

Cassone, A., Simonetti, N. \& Strippoli, V. (1973). Ultrastructural changes in the wall during germ-tube formation from blastospores of Candida albicans. Journal of General Microbiology 77, 417-426.

Cassone, A., Kerridge, D. \& Gale, E. F. (1979). Ultrastructural changes in the cell wall of Candida albicans following cessation of growth and their possible relationship to the development of polyene resistance. Journal of General Microbiology 110, 339 349.

Chattaway, F. W., Holmes, M. R. \& Barlow, A. J. E. (1968). Cell wall composition of the mycelial and blastospore forms of Candida albicans. Journal of General Microbiology 51, 367-376.

Elorza, M. V. \& SENTANDReu, R. (1969). Effect of cycloheximide on yeast cell wall synthesis. Biochemical and Biophysical Research Communications 36, 741-747.

Elorza, M. V., Rico, H. \& Sentandreu, R. (1983). Calcofluor white alters the assembly of chitin fibrils in Saccharomyces cerevisiae and Candida albicans cells. Journal of General Microbiology 129, 15771582.

Elorza, M. V., Murgui, A. \& Sentandreu, R. (1985). Dimorphism in Candida albicans: contribution of mannoproteins to the architecture of yeast and mycelial cell walls. Journal of General Microbiology 131, 2209-2216.

FARKAš, V. (1985). The fungal cell wall. In Fungal Protoplasts, pp. 3-29. Edited by J. F. Peberdy \& L. Ferenczy. New York \& Basel: Marcel Dekker.
Frevert, J. \& Ballou, C. E. (1984). Saccharomyces cerevisiae structural cell wall mannoprotein. Biochemistry 24, 753-759.

Geoghegan, W. O. \& Ackerman, G. A. (1977). Absorption of horseradish peroxidase ovomucoid and anti-immunoglobulin to colloidal gold for the indirect detection of concanavalin $\mathrm{A}$, wheat germ agglutinin and goat anti-human immunoglobulin $G$ on cell surfaces at the electron microscopic level. Journal of Histochemistry and Cytochemistry 25, 1187-1200.

Gibson, R. K., Buckey, C. E. \& Peberdy, J. F. (1976). Wall ultrastructure in regenerating protoplasts of Aspergillus nidulans. Protoplasma 89, 381-387.

GoOday, G. W., WoOdman, J., Cassone, A. \& Browne, C. A. (1985). Effect of nikkomycin on chitin spine formation in the diatom Thalassiosira fluviatis, and observations on its peptide uptake. FEMS Microbiology Letters 28, 335-340.

Gow, L. A. \& Selitrennikoff, C. P. (1984). Chitin synthetase of Neurospora crassa: inhibition by nikkomycin, polyoxin B and UDP. Current Microbiology 11, 211-216.

Haworth, W. N., Heath, R. L. \& Peat, S. (1941). The constitution of yeast mannan. Journal of the Chemical Society 833-842.

Hector, R. \& Braun, P. (1986). Synergistic action of nikkomycin $X$ and $Z$ with papulacandin $B$ on whole cells and regenerating protoplasts of Candida albicans. Antimicrobial Agents and Chemotherapy 29. 389-394.

Hilenski, L. L., NAider, F. \& Becker, J. M. (1986). Polyoxin D inhibits colloidal gold-wheat germ agglutinin labelling of chitin in dimorphic forms of Candida albicans. Journal of General Microbiology 132, 1441-1451.

Horisberger, M. \& Vonlanthen, M. (1977). Localization of mannan and chitin on thin sections of budding yeast with gold markers. Archives of Microbiology 115, 1-7.

KOPECKA, M. (1984). Lysis of growing cells of 
Saccharomyces cerevisiae induced by papulacandin B. Folia microbiologica 29, 441-449.

Lee, K. L., Buckley, H. R. \& CAmpbell, C. C. (1975). An amino acid liquid synthetic medium for development of mycelial and yeast forms of Candida albicans. Sabouraudia 13, 148-153.

LEHLE, L. \& TANNER, W. (1976). The specific site of tunicamicin inhibition in the formation of dolicholbound $N$-acetylglucosamine derivates. FEBS Letters 71, 167-170.

Miragall, F., Rico, H. \& Sentandreu, R. (1986). Changes in the plasma membrane of regenerating protoplasts of Candida albicans as revealed by freezefracture electron microscopy. Journal of General Microbiology 132, 2845-2853.

Molano, J., Bowers, B. \& Cabib, E. (1980). Distribution of chitin in the yeast cell wall. An ultrastructural and chemical study. Journal of Cell Biology 85, 199-212.

Murgui, A., Elorza, M. V. \& Sentandreu, R. (1985). Effect of papulacandin B and calcofluor white on the incorporation of mannoproteins in the wall of Candida albicans blastospores. Biochimica et biophysica acta 841, 215--222.

Murgui, A., Elorza, M. V. \& Sentandreu, R. (1986). Tunicamycin and papulacandin $B$ inhibit incorporation of specific mannoproteins into the wall of Candida albicans regenerating protoplasts. Biochimica et biophysica acta 884, 550-558.

NeČAs, O. \& Svoboda, A. (1985). Cell wall regeneration and protoplast reversion. In Fungal Protoplasts, pp. 115-135. Edited by J. F. Peberdy \& L. Ferenczy. New York \& Basel: Marcel Dekker.

Pastor, F. I. J., Valentin, E., Herrero, E. \& SENTANDREU, R. (1984). Structure of the Saccharomyces cerevisiae cell wall. Mannoproteins released by zymolyase and their contribution to wall architecture. Biochimica et biophysica acta 802, 292-300.

Perez, P., Garcia-Acha, 1. \& Duran, A. (1983). Effect of papulacandin B on the cell wall and growth of Geotrichum lactis. Journal of General Microbiology 129, 245-250.

Poulain, D., Tronchin, G., Dubremetz, J. F. \& BigueT, J. (1978). Ultrastructure of the cell wall of Candida albicans blastospores: study of its constitutive layers by the use of a cytochemical technique revealing polysaccharides. Annales de microbiologie 129A, 141-153.

Roberts, R. L., Bowers, B., Slater, M. \& Cabib, E. (1983). Chitin synthesis and localization in cell division cycle mutants of Saccharomyces cerevisiae. Molecular and Cellular Biology 3, 922-930.

Sentandreu, R., Herrero, E., Elorza, M. V., Rico, H. \& PAstoR, F. I. J. (1983). Synthesis and assembly of wall polymers on regenerating yeast protoplasts. Experientia (supplement) 46, 187-195.

Shepherd, M. G., Poulter, R. T. M. \& Sullivan, P. A. (1985). Candida albicans: biology, genetics and pathogenicity. Annual Review of Microbiology 39, 579-614.

Shibata, N., Mizugami, K., Takano, K. \& Suzuki, S. (1983). Isolation of mannan-protein complexes from viable cells of Saccharomyces cerevisiae X2180-1A wild type and Saccharomyces cerevisiae X-2180-1 A-5 mutant strains by the action of zymolyase 60000 . Journal of Bacteriology 156, 552-558.

SIETSMA, J. H. \& WESSELS, J. G. H. (1981). Solubility of $(1 \rightarrow 3)-\beta-D /(1 \rightarrow 6)-\beta$-D-glucan in fungal walls: importance of presumed linkage between glucan and chitin. Journal of General Microbiology 125, 209-212.

SonnenberG, A. S. M., Sietsma, J. H. \& Wessels, J. G. H. (1982). Biosynthesis of alkali-insoluble cell wall glucan in Schizophyllum commune protoplasts. Journal of General Microbiology 128, 2667-2674.

SPURR, A. R. (1969). A low density epoxy resin embedding medium for electron microscopy. Journal of Ultrastructure Research 26, 31-38.

StagG, C. M. \& Feather, M. S. (1973). The characterization of chitin associated D-glucan from the cell walls of Aspergillus niger. Biochimica et biophysica acta 320, 64-72.

Sullivan, P. A., Yin, C. Y., Molloy, C., Templeton, M. D. \& SHEPHERD, M. G. (1983). An analysis of the metabolism and cell wall composition of Candida albicans during germ-tube formation. Canadian Journal of Microbiology 29, 1514-1525.

TKaCZ, J. S. \& LAMPEN, J. O. (1975). Tunicamycin inhibition of polyisoprenyl $N$-acetylglucosaminyl pyrophosphate formation in calf-liver microsomes. Biochemical and Biophysical Research Communications 65, 248-257.

Tronchin, G., Poulain, D. \& Biguet, J. (1979). Etudes cytochimiques et ultrastructurales de la paroi de Candida albicans. I. Localization des mannanes par utilisation de Concanavaline A sur coupes ultrafines. Archives of Microbiology 123, 245-249.

Tronchin, G., Poulain, D., Herbaut, J. \& Biguet, J. (1981). Localization of chitin in the cell wall of Candida albicans by means of wheat germ agglutinin. Fluorescence and ultrastructural studies. European Journal of Cell Biology 26, 121-128.

Valentin, E., Herrero, E. \& Sentandreu, R. (1986). Incorporation of mannoproteins into the walls of Aculeacin A-treated yeast cells. Archives of Microbiology 146, 214-220.

dE Vries, O. M. H. \& Wessels, J. G. H. (1975). Chemical analysis of cell wall regeneration and reversion of protoplasts from Schizophyllum commune. Archives of Microbiology 102, 209-218.

Wessels, J. G. H., Sietsma, J. H. \& Sonnenberg, A. S. M. (1983). Wall synthesis and assembly during morphogenesis in Schizophyllum commune. Journal of General Microbiology 129, 1607-1616.

Zlotnix, H., Fernandez, M. P., Bowers, B. \& CABIB, E. (1984). Saccharomyces cerevisiae mannoproteins form an external cell wall layer that determines wall porosity. Journal of Bacteriology 159, 1018-1026. 